My attempt at lithectasy was, I fear, a poor one. With a proper tent, or a three-bladed dilator, or both, the urethra might possibly have been sufficiently dilated to permit the removal of the stone. At any rate, if I meet such another case, and the stone is of moderate size, I will give this method a fair trial before proceeding to lithotomy. In attempting to crush the stone as I did, I did more harm than good.

\section{A CASE OF EAR-SNEEZING.}

BY JAMES RUSSELL, M.D., F.R.C.P., Physician to the Birmingham General Hospital.

AN explanation of the prominent phenomenon in the following case, viz., the constant attacks of sneezing through two days and nights, occasioned apparently by acute inflammation of the middle ear, will be found in a short paper by Dr. Lockhart Clarke on the Phenomena of Ear-Cough, in the number of this JouRnAL for January 15th, I870. Were argument needed for transferring the reasoning therein from the process of coughing to that of sneezing, the concluding sentence of that paper would afford it : "With regard to the anatomical connection and the mechanism by which I have shown that impressions made on the vagus and on the incident fibres of the trifacial and spinal nerves may call into action the whole class of respiratory muscles, see my memoir." It appears, also, that some sudden change within the cavity of the tympanum in my patient, a change followed by instant deafness, acted upon the heart, through the inhibitory influence of the vagus, and produced fainting. It is also worth noting that there was no vertigo present, the labyrinth having probably escaped. I have commented on another occasion upon the distinction between vertigo and fainting, in connection with a case of the so-called gastric vertigo.

A man aged 56, of nervous temperament, an out-patient of the Birmingham General Hospital, was in his usual health a fortnight ago, when he was suddenly taken with " a kind of gaping and sneezing"; the gaping seemed to come from his heart. The sneezing was incessant during the next two days and night; "he could not tell the quantity of times he sneezed". At last, in the afternoon of the second day, after a dreadful sneezing fit, he tumbled down, and was unconscious for two or three minutes; on recovering, he was completely deaf, so much so that, not knowing what had happened, and crossing the street soon afterwards, he narrowly escaped being knocked down by a passing vehicle. On the following afternoon, he began to hear on the left side, but the sound seemed "to cume the contrary way"; if from the front, it appeared to come from behind ; if it started from one side of the street, it appeared to come from the opposite side. Ever since, he has been " in agony" from a thumping through the ears, like a pulse beating very quickly, with a constant whizzing and a flutter in the ears. When the thumping ceased, "it was like a toothache behind his ears". He has not had any cough nor vertigo whatever. Dr. Malet, our house-physician, examined the ears for me, and found the left ear full of wax; this having been removed, it appeared that both tympana were acutely inflamed at the attachment of the ossicles, the right very severely, being almost in a state of suppuration. After syringing, I found that the patient distinguished a faintly ticking watch only within three-quarters of an inch of his left ear ; a loudly ticking watch, at eight inches. On the right side, he heard nothing, even when the watch was applied to the ear or to the cranium.

\section{CASE OF "ANGINA LUDOVICI".}

\section{By JOHN A. ERSKINE STUART, L.R.C.S.Ed., Dunse, N.B.}

ON April 29th, I879, I was called to the country to visit a child six months old, who was troubled with a swelling in the neck. On examining the little sufferer, a state of things presented itself which to me was totally unfamiliar. I found a hard brawny swelling extending over the whole front of the neck, from the lower jaw to the sternum. To look at, there was something of the appearance of emphysema; but, on putting the fingers on the swelling, the hard brawny feeling at once made itself 'plain. The skin over the greater part of the tumour was natural in colour; but, immediately below the symphysis of the lower jaw, a black spot, of the size of a shilling, presented itself, surrounded by a bluish congested margin, the whole discoloration amounting to about the size of a florin piece at most. The face was also much swollen, and pitted on pressure, evidently due to pressure on the cervical veins preventing return of blood. On palpating the swelling, there was no indication of fluctuation at any point, with the exception of the discoloured circle, where indistinct fluctuation could be detected. The parotid and submaxillary glands were much enlarged and hard. The child's tongue was foul. Nothing could be discovered amiss with the throat on examination, conducted with difficulty, on account of the stiffness of the jaws. The pulse was exceedingly weak, and the skin very hot. The pupils were enormously dilated. The infant was cvidently in articulo mortis, having been ill for two days previous to my only visit.

I ordered poultices to the swelling, to be repeated frequently, gave 2 few grains of hydrargyrum cum cretâ, and ordered the child to be kept on milk diet entirely. The patient had been brought up on the bottle; but, when this disease developed itself, the mother had to resort to feeding by hand. I gave a very gloomy prognosis, and was not much surprised when the father called next morning to say that the child had died early on that day.

REMARKS. - In no work on practice of medicine have I seen a dis ease described similar to this. In signing the death-certificate, I assigned the cause of death to cervical abscess of three days' duration. Shortly afterwards, I heard that Professor Grainger Stewart of Edinburgh University had lectured during the winter on a newly discovered disease, called " angina Ludovici"; and, finding that my case presented the exact symptoms detailed to me by one who had heard the lecture, I am convinced that this was a case of that disease. The pathology of the disease is simply an inflammation of the cellular tissue of the neck, going on to suppuration. Another case was seen in this district about the same time by another practitioner, the result being successful, if remember rightly. Whether I should have opened the tumour at the soft congested spot on that evening now suggests itself to me as a retrospective question. There were certainly no indications for an immediate incision. No doubt an early antiseptic incision might have given the infant relief; but the probability is that it would have sunk, as it had always been a puny weakly creature.

\section{A T RESI A VAGI N $Æ$.}

\section{By JOHI HUSBAND, F.R.C.S.E., Ajmere, South India.}

ON April 17th, 1878, Narayani, a young woman aged 22, was admitte into the Female Mission Hospital, Ajmere, anxious to see whether anything could be done to relieve her condition of occluded vagina. She began to menstruate when she was twelve years of age; the menstruad flow had appeared at regular monthly intervals ever since; she passed her monthly periods with the minimum amount of suffering; and the fluid was normal in quantity. She stated, moreover, that her parents had married her to her present husband without indicating the condition of affairs, the consequence of which was that he treated her with great contempt, refused to give her jewels to wear, or even decent clothes to put on; and that she was known in the neighbourhood as a "hinjri" (hermaphrodite), and clespised of all her neighbours. On making a physical examination, I found that there was not the slightest trace of a vagina. At the upper part of what should have been the vaginal orifice, there was a small pouch-like projection, which turned out to be the urethra greatly dilated, which only admitted the tip of my little finger. With the finger in the rectum, there was no difficulty in making out the existence of the uterus, the mouth of which, opening into the urethral canal, accounted for the ease with which the menstrual function had been performed. The woman had an additional finger for each hand and toe for each foot.

Next day, with the advice and co-operation of the late Dr. Murray, civil surgeon, Ajmere, I proceeded to operate. The patient having been anæsthetised, and placed in the usual lithotomy position, Dr. Murray took charge of the staff introduced through the urethra into the bladder, while I procceded to make a channel through the tissues between the urethra and rectum up to the uterus. I first made a transverse incision in front of the anus ; and then, with a little gentle cutting and a good deal of tearing up of tissue with the fingers, a canal to the uterus was soon opened up, through which the os uteri could be distinctly felt. With the urethra held well up under the pubic arch, and the index finger of the left hand in the rectum, there was no difficulty in knowing where to go, and the operation was soon over. A certain amount of contraction of the tissues occurred, but the canal remained useful for all purposes. A plug of lint, smeared with carbolic oil, was inserted into the wound, and the patient kept in the recumbent position for a number of days. To keep the canal patent, glass plugs were not available; but one made of lac was found the best substitute. The woman herself being extremely anxious that the operation should be successful, did her best to carry out instructions. The wound was progressing so satisfactorily that she left the hospital on May 3rd. A few months after her return home, the woman returned in great glee to tell me she was pregnant. A intervals during her pregnancy, she came to have the canal examined. Fortunately, the child was a small one. The labour passed off with the 